\title{
REPENSANDO QUESTÕES SOBRE MUDANÇA, AFETO E RESISTÊNCIA NA IMPLEMENTAÇÃO DE SI
}

\author{
Maria Amélia de Mesquita Fetzner \\ amelia.fetzner@gmail.com \\ Empresa Brasileira de Infraestrutura Aeroportuária - Porto Alegre, RS / Brasil \\ Henrique Mello Rodrigues de Freitas \\ hf@ea.ufrgs.br \\ Universidade Federal do Rio Grande do Sul - Porto Alegre, RS / Brasil
}

\begin{abstract}
Recebido em 19/02/2010
Aprovado em 28/04/2011

Disponibilizado em 01/04/2012

Avaliado pelo sistema double blind review

Revista Eletrônica de Administração

Editor: Luís Felipe Nascimento

ISSN 1413-2311 (versão on-line)

Editada pela Escola de Administração da Universidade Federal do Rio Grande do Sul.

Periodicidade: Quadrimestral
\end{abstract}

Sistema requerido: Adobe Acrobat Read.

\section{RESUMO}

A importância das pessoas no sucesso de Sistemas de Informação (SI) é amplamente reconhecida. Empresas não mudam, se as pessoas que as integram também não mudarem, e qualquer iniciativa de introdução de um novo sistema traz, em seu bojo, a ideia de mudança. Entretanto, a grande maioria dos estudos na área privilegia aspectos cognitivos e racionais e são crescentes as sugestões para estudos que contemplem também a afetividade. Este artigo atende a esta sugestão e apresenta um estudo exploratório realizado numa empresa privada, mediante entrevistas com usuários de um sistema ERP - Enterprise Resource Planning, no período de pós-implementação, no ano de 2008. O objetivo central do estudo foi o entendimento das mudanças, no âmbito dos indivíduos, associadas à introdução do sistema. Para tal apoiou-se em referenciais teóricos sobre implementação de Tecnologia de Informação (TI), mudança, afetividade e resistência. Os resultados mostraram o contexto da implementação, os tipos de mudança, os significados, os afetos e resistências envolvidos no processo. As conclusões salientam a interação entre componentes cognitivos e afetivos; o modo pelo qual as pessoas constroem a vivência da mudança associada com TI/SI (inclusive quanto à resistência) a partir de fatores, tais como suas circunstâncias pessoais, sua relação com a empresa e a forma como esta conduz o processo; e ainda o paradoxo que se cria quando a satisfação com a informática gera necessidades crescentes. Ao final, apresentamos contribuições, limites do estudo e sugestões para pesquisas posteriores.

Palavras-chave: mudança, afetividade, resistência, sistemas, tecnologia de informação, implementação. 
Repensando questões sobre mudança, afeto e resistência na implementação de SI

\title{
RETHINKING QUESTIONS ABOUT CHANGE, AFFECTION AND RESISTANCE IN IS IMPLEMENTATION
}

\begin{abstract}
The importance of the people in the success of Information Systems (IS) is widely recognized. Companies do not change if the people who integrate them do not change, and any initiative of introducing a new system brings in its core the idea of change. However, the great majority of the studies in this area privileges cognitive and rational aspects, and suggestions for studies that also contemplate the affectivity are increasing. This article is concerned with these suggestions and presents an exploratory study carried out in a private company, by means of interviews with users of an ERP system - Enterprise Resource Planning, in the period of its post-implementation, in the year of 2008. The main objective of the study was the understanding of these changes, in the scope of the individuals, associated to the introduction of the system. For this purpose it was supported with theoretical concepts on the implementation of Information Technology (IT), change, affectivity and resistance. The results showed the context of implementation, the types of change, the meanings, the affection and the resistance involved in the process. The conclusions highlight the interaction between cognitive and affective components; the way through which people construct the experience of change associated with IT/IS (also in regards to resistance) through factors such as their personal circumstances, their relation with the company and the way in which it conducts the process; and also the paradox that is created when the satisfaction with computing generates crescent needs. In the end, we present contributions, limitations of this study and suggestions for further research.
\end{abstract}

Keywords: change, affection, resistance, systems, information technology, implementation.

\section{INTRODUÇÃO}

O Prof. Michael Myers, tratando sobre temas de pesquisa em Sistemas de Informação no seminário Issues in Information System Research ${ }^{i}$,referiu como alguns tópicos de pesquisa são mais permanentes, enquanto outros "vêm e vão". Ele disse que, nos temas permanentes, sempre é possível efetuar melhorias e desenvolvimentos e entre estes incluiu o da implementação de TI. Embora tenha enfatizado novas tecnologias, o mesmo argumento vale para tecnologias bem estabelecidas, quando novas visões e desenvolvimentos surgem de facetas anteriormente menos exploradas ou de perspectivas diversas das habituais.

Acreditamos que o tópico da mudança, no âmbito dos indivíduos e associada com a implementação de TI/SI, enseje novos elementos para a compreensão de processos deste tipo. A relevância do assunto se deve ao fato de que as empresas não mudam se as pessoas que as integram não mudarem e à condição que este tema oferece para investigar a afetividade relacionada à experiência com SI, tema sugerido crescentemente na área (ORLIKOWSKI, 2000; CIBORRA, 2002; MCGRATH, 2006; SACCOL; REINHARD, 2006). 
A mudança no plano individual (GEORGE; JONES, 2001) conjuga elementos cognitivos, afetivos e comportamentais, e o seu estudo se insere no contexto de abordagens que reconhecem elementos emocionais envolvidos na experiência com SI. Abordagens deste tipo representam uma reação ao pensamento baseado em modelos racionais, que por muito tempo foi dominante nesta área (RODRIGUES FILHO; LUDMER, 2005; MCGRATH, 2006).

$\mathrm{O}$ que acontece com as pessoas envolvidas, quando uma empresa se decide a introduzir uma nova TI? Por que, em algumas empresas, mesmo sem ações planejadas, a implementação é bem-sucedida? E por que em outras, com mais estrutura, não é? Sempre devemos esperar resistências a um SI? Qualquer reação contrária é sinal de resistência? Neste artigo, o assunto é examinado à luz dos resultados de um estudo que teve por objetivo examinar o modo pelo qual os indivíduos vivenciam as mudanças associadas com a implementação de um SI e, em especial, o significado a elas atribuído e o papel representado pela afetividade neste processo.

O artigo apresenta a seguir uma revisão teórica sobre a relação entre implementação de TI e mudança, afetividade e resistência nestes processos. Segue-se a descrição da pesquisa e dos principais achados. Na discussão, integramos a teoria à análise dos resultados, para construir a compreensão do caso e, nas considerações finais, apresentamos as contribuições e os limites do estudo, bem como sugestões para investigações posteriores.

\section{A EXPERIÊNCIA DAS PESSOAS COM SISTEMAS DE INFORMAÇÃO}

\subsection{IMPLEMENTAÇÃO DE TI/SI E MUDANÇA}

Cada vez mais observamos uma associação entre TI e MUDANÇA no cenário organizacional. Esta constatação não deveria causar surpresa, pois, hoje, uma intervenção que pretenda uma mudança organizacional dificilmente prescinde de tecnologia, assim como é notório que toda introdução de tecnologia demanda ou traz como conseqüência algum ajuste organizacional. Barret, Grant e Wailes (2006) revisam a literatura sobre o assunto e indicam a integração de contribuições entre o campo de SI e o de Estudos Organizacionais (EO) para prover insights para o seu entendimento. A seguir, sintetizamos as principais linhas de debate identificadas pelos autores, salientando aquelas relacionadas ao presente estudo.

$\mathrm{Na}$ literatura de EO, os desenvolvimentos mais significativos versam sobre a natureza do processo de mudança, o impacto de instituições sociais e econômicas sobre a mudança organizacional e os estudos discursivos sobre o tema. Os estudos sobre processo, em especial, têm contribuído para auxiliar a explicar os fatores ligados a falhas em iniciativas de mudança 
Repensando questões sobre mudança, afeto e resistência na implementação de SI

(e daí em projetos de TI) e enfocado reações e fontes de resistência à mudança como inerentes ao processo e não como inapropriadas. Em geral, como observam os autores recém citados, estudos em EO têm abordado, de forma menos direta do que os em SI, o entendimento da natureza da tecnologia e o modo pelo qual ela se relaciona à mudança organizacional.

Na literatura de SI, os debates envolvem: o papel da materialidade e da agência na relação entre a TI e as pessoas; a importância do processo, do contexto e de características da tecnologia para examinar a TI e a estruturação nas organizações; as abordagens discursivas e a análise "situada" (situatedness) das tecnologias na prática. Neste grupo, uma das principais correntes, na qual incluem Ciborra (2001), debate o papel da emoção na ação situada.

Para avançar na compreensão da natureza da mudança em relação com a TI, é preciso, de acordo com os mesmos autores, ir além de uma visão abstrata e determinista sobre a tecnologia e considerar também o caráter complexo, contingente e socialmente construído da mudança revelado pelos EO, além de construir um entendimento com mais nuances sobre a tecnologia, tomando como bases a sua natureza material e social e a tecnologia em uso.

Vaast e Walsham (2005) concebem a mudança em práticas de trabalho como um processo dinâmico de consonância/dissonância, resultado de transformações no modo como os agentes atuam e dão sentido às suas ações e às do ambiente (suas representações). Representações são definidas como um grupo de idéias e conhecimentos estáveis e socialmente compartilhados que os agentes elaboram para dar sentido ao seu ambiente. Usuários são considerados agentes sociais que representam o mundo e os vários aspectos de suas experiências, de acordo com o contexto social em que estão inseridos. Agentes de um mesmo ambiente tendem a representar o mundo de forma similar (ou até mesmo idêntica), e suas representações mediam suas percepções e entendimento da realidade. As representações são constantemente reelaboradas em função da atividade reflexiva dos agentes. E, se estes mudam o modo como representam o ambiente, também mudam o seu uso da tecnologia e as suas práticas. Conforme os agentes experimentam dissonância entre ações, representações e práticas, gradualmente adaptam o modo pelo qual representam o seu ambiente de trabalho e como atuam, de modo a restabelecer a consonância. Se esta adaptação é socialmente partilhada e repetida ao longo do tempo, mudam as práticas, as representações e a TI em uso.

Representações diferenciam-se de duas noções usadas em SI. Uma delas é a de Sensemaking - criação de sentido (WEICK; SUTCLIFFE; OBSTFELD, 2005, p. 409), que "implica converter circunstâncias em uma situação que seja explicitamente compreendida em palavras, e que sirva como um trampolim para a ação" e a outra é a de Technological Frames - Frames Tecnológicos, definidos como estruturas cognitivas compartilhadas por um grupo REAd I Porto Alegre - Edição 71 - N 1 - janeiro/abril 2012 - p.1-26 
Maria Amélia de Mesquita Fetzner \& Henrique Mello Rodrigues de Freitas

ou comunidade, que dizem respeito a "pressupostos, expectativas e conhecimentos usados para entender a tecnologia nas organizações" (ORLIKOWSKI; GASH, 1994, p.178).

Os autores supracitados compartilham a idéia de que experiência com uma TI envolve emoções, e sugerem a realização de estudos sobre o tema. Para tal, nós propomos a perspectiva do processo de mudança individual, definido por George e Jones (2001, p. 421) como "um processo de criação de sentido individual e grupal que tem lugar num contexto social e é o produto da constante e contínua produção e interação humana em contextos organizacionais".

O modelo de George e Jones para explicar a mudança individual é cíclico, e considera que, nas organizações, as pessoas usam esquemas para processar informações e dar sentido aos acontecimentos, num processo investido de afetividade. Sintetizando, quando as pessoas podem perceber, interpretar e dar sentido a um acontecimento da vida organizacional de acordo com esquemas preexistentes e não forem encontradas discrepâncias ou incongruências, a tendência será a de permanecerem num certo equilíbrio, sem ímpeto para mudanças ou alterações de perspectiva. Contudo, se houver discrepância, pode ser desencadeada uma reação emocional e esta poderá dar início a um processo de mudança, com alteração de esquemas. As emoções atuam como sinais de que devemos prestar atenção em algo, indicam a necessidade de mudança ou, quando se tornam estados menos intensos, influenciam o processamento de informação. Novos esquemas incluem tanto o conhecimento organizado como o afeto associado à mudança. A noção de esquema diferencia-se da de representações pelo sentido individual e por envolver afetos, enquanto as representações enfatizam cognição.

\subsection{IMPLEMENTAÇÃO DE TI E AFETIVIDADE}

McGrath (2006) revisa o tema da emoção na literatura de SI, apontando três atitudes dominantes no campo: a) nada dizer sobre emoções, assumindo que SI envolve um processo puramente racional; b) citar a emoção 'en passant', sem dar-lhe maior atenção analítica e c) examinar as emoções através de um esforço analítico. No segundo grupo, McGrath (2006) inclui Orlikowski (2000) e no terceiro Ciborra $(2002,2006)$ e ela própria. A seguir revisamos as proposições destes autores e de outros, que também agregam uma contribuição ao tema.

Conforme McGrath (2006), a pesquisa de Orlikowski é focada em respostas cognitivas dos atores às Tecnologias de Informação e Comunicação (TICs) ${ }^{\text {ii }}$. De fato, Orlikowski não dá centralidade na análise às emoções, mesmo reconhecendo que as tecnologias, além de seu significado intelectual, tenham conexões afetivas para as pessoas. Para esta autora, embora as tecnologias possam incorporar propriedades materiais e simbólicas particulares, é pela interação repetida das pessoas com tecnologias que certas propriedades se tornam implicadas

REAd I Porto Alegre - Edição 71 - N 1 - janeiro/abril 2012 - p.1-26 
Repensando questões sobre mudança, afeto e resistência na implementação de SI

num processo de estruturação, de forma que "a prática social recorrente resultante produz e reproduz uma estrutura particular de uso da tecnologia" (ORLIKOWSKI, 2000, p. 407). São as chamadas "tecnologias na prática" (technologies-in-practice), constituídas a partir de conhecimentos, aptidões, poder, suposições e experiências prévias das pessoas. A prática com uma nova TI não é um processo totalmente aberto, pois as tecnologias como artefatos têm propriedades que impõem limites ao uso. A mudança é situada, descrita como um ajustamento progressivo e incremental e também um processo de adaptação pelas pessoas, no qual a improvisação pode surgir em resposta a oportunidades, desafios, problemas e avarias.

Para Zorn (2002), a emoção é parte da experiência de trabalho das pessoas e desempenha um papel-chave na mudança organizacional baseada em TICs. Zorn constatou em um estudo etnográfico que a implantação de novas TICs e as experiências emocionais ligadas a ela são fenômenos ambíguos a serem interpretados e, portanto, suscetíveis de influência na interação, chegando às conclusões a seguir. Primeiro, a ambigüidade de emoção e novas TICs, demonstrada por abertura ou receios à mudança, por comentários positivos e negativos, ou por múltiplas interpretações e avaliações. Reconhecer a ambigüidade é crucial no sucesso de uma iniciativa de mudança, pois essa possibilita aos indivíduos a influência sobre outros na interpretação de emoções e na construção da experiência num modo particular, pela via da comunicação. Terceiro, as pessoas usam a expressão emocional de modo instrumental. Expressões de emoções positivas podem servir para manter e apoiar relações de trabalho com colegas e aliviar tensões ao lidar, por exemplo, com a frustração e com o estresse de aprender um sistema novo e de cometer erros, e para se conectar com colegas. A expressão de emoções negativas pode servir para administrar relações de poder, para resistir a uma mudança temida, para sinalizar algo que não está bem e que requer refinamentos técnicos e suporte. Em quarto, agentes de mudança realizam um trabalho emocional para criar a mudança, usando a expressão de suas emoções segundo o seu papel e visando o alcance de metas organizacionais. Ainda, as pessoas se baseiam em regras para exposição emocional, sancionadas cultural e organizacionalmente para alcançar seus objetivos e lidar com o clima emocional.

Cenfetelli (2004) destaca o fato de que as interações das pessoas com a tecnologia são mais do que apenas racionais e devem apreciar o amplo espectro de emoções que estas são capazes de sentir. Baseado em estudo de campo, totalmente conduzido online e enfocando a condição de uso inicial, este autor chegou às seguintes conclusões: 1) As emoções contribuem de forma importante para o uso de tecnologia. Usuários mais do que tomadores racionais de decisão, também são influenciados por seus sentimentos; 2) Emoções negativas e positivas 
agem separadamente, sendo que as negativas têm mais efeito sobre o uso, influenciando mais fortemente crenças e intenções finais. Ele adverte que do ponto de vista de investimento é melhor evitar criar emoções negativas nos usuários do que assegurar positivas; 3) Emoções têm uma natureza multidimensional. Ele define como emoções positivas: alegria, felicidade, contentamento, afeição (carinho) e como negativas: ansiedade, irritação, preocupação, arrependimento, desgosto, raiva, nervosismo, medo; 4) É essencial avaliar reações emocionais e cognitivas quando analisando como usuários reagem à tecnologia e se irão adotá-la e usá-la.

Ciborra $(2002,2006)$ examina como as pessoas, em suas práticas cotidianas de trabalho, interagem com SI, questionando a visão proposta pelas metodologias de sistema estruturadas, que, para ele, tendem a se afastar do dia a dia dos procedimentos humanos, refugiando-se em disposições e normas abstratas. Ele explica a adoção de uma nova tecnologia por meio de uma metáfora, a "Metáfora da Hospitalidade", e realça as condições existenciais, estados de espírito e emoções dos atores no processo. Ciborra examina o tema da emoção em SI a partir da retomada dos conceitos de situado, situação e de "estar situado", apontando que a expressão tem sido usada numa concepção liberal, distanciada do significado original dado por Heidegger. Esclarece que situatedness no seu significado original refere-se "tanto a circunstâncias em andamento ou emergentes, como ao mundo ao redor e à situação interior do ator" (CIBORRA, 2006, p. 130), enquanto várias abordagens (ORLIKOWSKI, 2000) não chegam a capturar o sentido fenomenológico do termo, que é usado sem a percepção de contraste com o que seria puramente mental ou cognitivo, e tampouco sem explorar referências a emoções e humores. Resulta que o termo tem ficado restrito ao significado de "contexto ou circunstâncias emergente de ação e conhecimento" (CIBORRA, 2006, p. 131).

A Metáfora da Hospitalidade destaca humores e emoções na experiência cotidiana com tecnologia e isto é ilustrado nos resultados do estudo de Saccol e Reinhard (2006) sobre adoção de um dispositivo móvel, junto a um banco brasileiro. Os autores constataram o caráter dúbio da tecnologia, tal como concebido pela Metáfora, verificando elementos como entusiasmo, frustração, ressentimento, mudança de humores e que emoções relacionadas a essa tecnologia são tanto do tipo 'positivo' quanto do 'negativo'(grifo dos autores).

Para McGrath (2006) as emoções estão implicadas em todas as experiências de vida e na constituição da conduta moral de um indivíduo. A inovação em SI - o conceito engloba SI e mudança - é vista como um esforço moral e político, no qual as crenças e sentimentos são constantemente testados. A aceitação de determinadas práticas pelos indivíduos não depende só de conhecimento e razão socialmente construídos. A racionalidade técnica usual na 
Repensando questões sobre mudança, afeto e resistência na implementação de SI

condução de implementações é confrontada com uma racionalidade reflexiva. Esta inclui a perspectiva sobre conduta moral fundada sobre crenças e sentimentos inter-relacionados, num regime no qual emocionalidade e racionalidade se constituem mutuamente. As pessoas agem segundo crenças sobre o que seja uma conduta apropriada na sociedade que integram e, também, de acordo com o modo como pelo qual se constituem sujeitos de suas ações e de crenças específicas sobre que é correto ou não. Comportamentos com emocionalidade podem não ser simplesmente indicativos de preocupações cognitivas mais importantes ou uma forma inapropriada de resistência à mudança e sugerir direções legítimas para uma organização.

\subsection{RESISTÊNCIA À MUDANÇA}

Resistência à mudança é um dos temas freqüentes em estudos sobre mudança organizacional, e muitos destes tenderam a considerar reações adversas à mudança, incluindo as resistências, como problemáticas, ou até irracionais, mas passíveis de solução por ações de Gestão da Mudança (GM), como comunicação com empregados e técnicas de envolvimento. As abordagens de GM ofereceram uma gama de razões potenciais para os funcionários resistirem à mudança, tais como o resultado de uma aversão inerente à mudança, o apego ao conhecido, o desejo de evitar a incerteza, os interesses pessoais, a falta de entendimento sobre a necessidade de mudança. Porém, falharam em teorizar sobre as bases para tal resistência, algumas das quais podem ser preocupações legítimas, tal como o impacto da mudança sobre o bem-estar e desempenho individual ou organizacional (HARLEY et al., 2006).

Hernandez e Caldas (2001) examinam os modelos predominantes e os pressupostos sobre os quais foram construídas as "receitas" (aspas dos autores) para lidar com as resistências à mudança, argumentando que essas não têm sido eficientes nem na sua prevenção e nem na sua superação, em razão de estarem baseadas em pressupostos hoje contestados por teóricos e práticos. O Quadro 1 explicita o pensamento dos autores.

Quadro 1-Pressupostos clássicos sobre resistência à mudança e possíveis contrapressupostos

\begin{tabular}{|l|l|}
\hline \multicolumn{1}{|c|}{ Pressupostos } & \multicolumn{1}{c|}{ Contrapressupostos } \\
\hline $\begin{array}{l}\text { A resistência à mudança* é um "fato da vida” e } \\
\text { deve acontecer durante qualquer intervenção } \\
\text { organizacional. } \\
\text { * “qualquer conduta que objetiva manter o status } \\
\text { quo em face da pressão para modificá-lo" (p.32). }\end{array}$ & $\begin{array}{l}\text { A resistência é escassa/somente acontecerá em } \\
\text { circunstâncias excepcionais. } \\
\text { Ao tentar preveni-la, os agentes de mudança acabam } \\
\text { contribuindo para sua ocorrência ou agravamento. } \\
\text { A resistência é um comportamento alardeado pelos } \\
\text { detentores de poder e pelos agentes de mudança quando } \\
\text { são desafiados em seus privilégios ou ações. }\end{array}$ \\
\hline $\begin{array}{l}\text { A resistência à mudança é maléfica aos esforços } \\
\text { de mudança organizacional. }\end{array}$ & $\begin{array}{l}\text { A resistência é um fenômeno saudável e contributivo } \\
\text { A resistência é usada como uma desculpa para processos } \\
\text { de mudança fracassados ou inadequadamente desenhados. }\end{array}$ \\
\hline
\end{tabular}




\begin{tabular}{|l|l|}
\hline $\begin{array}{l}\text { Os seres humanos são naturalmente resistentes à } \\
\text { mudança. }\end{array}$ & $\begin{array}{l}\text { Os seres humanos resistem à perda, mas desejam a } \\
\text { mudança: tal necessidade tipicamente se sobrepõe ao medo } \\
\text { do desconhecido. }\end{array}$ \\
\hline $\begin{array}{l}\text { Os empregados são os atores organizacionais } \\
\text { com maior probabilidade de resistir à mudança. }\end{array}$ & $\begin{array}{l}\text { A resistência - quando ocorre - pode acontecer entre os } \\
\text { gestores, agentes de mudança e empregados (derivado da } \\
\text { proposição original de Lewin). }\end{array}$ \\
\hline $\begin{array}{l}\text { A resistência à mudança é um fenômeno } \\
\text { grupal/coletivo. }\end{array}$ & $\begin{array}{l}\text { A resistência é tanto individual quanto coletiva - a } \\
\text { resistência vai variar de uma pessoa para outra, em função } \\
\text { de muitos fatores situacionais e de percepção. }\end{array}$ \\
\hline
\end{tabular}

Fonte: Hernandez e Caldas, 2001, p.37.

Hernandez e Caldas propõem um modelo teórico de resistência individual, baseado no processo perceptivo em situações de mudança organizacional, com sete estágios que se desenvolvem a partir da exposição aos estímulos do ambiente (exposição à mudança ou inovação), cuja natureza frequentemente é ambígua, e a adoção de comportamentos varia entre: adoção de um comportamento resistente; decisão de superar a resistência; indecisão; adoção espontânea da mudança. Resistências e emoções são localizadas ao final do processo.

Silva e Vergara (2003) criticam as fórmulas de GM voltadas a que as pessoas assimilem um sentido comum e afirmam que o consenso que pode transparecer no discurso é sempre fruto de uma linguagem negociada e de um texto produzido e validado na ação conjunta cotidiana. A mudança é um fenômeno abstrato, de múltiplas faces, percebido de maneira muito diversificada, tais como implacável, desestabilizadora, frustrante, desafiadora, progressista, renovadora e não há como lhe atribuir um significado comum, mesmo com percepções coincidentes entre funcionários de uma empresa. São diversos os tipos de sentimentos, as interpretações, as implicações percebidas, individual ou coletivamente.

Para estes autores, é necessário reconhecer o ser humano como ator e sujeito, isto é, como um indivíduo com consciência do seu papel na construção da realidade e para quem sua existência e sua ação na organização têm sentido, pois em geral as pessoas se vêem como objetos, atores guiados ou nas hipóteses favoráveis como agentes das mudanças. Independentemente do modo pelo qual a organização dirige o processo, dois elementos associam-se à condição de sujeito: a (re) descoberta das próprias potencialidades e do próprio valor. Surgem de oportunidades para atualizar conhecimentos, participar, expor opiniões, aproximar-se de instâncias superiores e, sobretudo, da chance de compartilhar com as pessoas à volta dúvidas, sentimentos, expectativas, medos, concordâncias e discordâncias. Já a falta de definições sobre políticas de pessoal, futuro da organização, objetivos e rumos do processo, distanciamento entre níveis hierárquicos, conflitos entre a organização e seus empregados, ou a diferença no tratamento entre empregados podem dificultar o processo de subjetivação. 
Repensando questões sobre mudança, afeto e resistência na implementação de SI

O mito da resistência à mudança existe para aqueles que não conseguem conceber obstáculos a uma ação racional (itálico no original) ou como algo que ajuda as pessoas a explicarem aquilo que não conseguem entender e a lidar com a situação. As resistências são manifestações de emoções e quer sejam positivas ou negativas devem poder ser expressas para que os indivíduos possam resolver suas ansiedades e as empresas tenham a oportunidade de captar as reais dificuldades para que as mudanças ocorram (SILVA; VERGARA, 2003).

\section{MÉTODO}

O objetivo central da investigação foi o entendimento das mudanças, no âmbito dos indivíduos, associadas à implementação de um SI e, em especial, o significado a elas atribuído e o papel representado pela afetividade. O estudo foi exploratório e examinou a percepção de um grupo de usuários, em uma empresa privada, na fase de pós-implementação de um $E R P$.

A abordagem foi qualitativa e guiada por idéias de Walsham, que clarifica a visão epistemológica subjacente à pesquisa com o método interpretativista, dizendo que "nossas teorias sobre a realidade são maneiras de dar sentido ao mundo, e significados compartilhados são uma forma de intersubjetividade, mais do que de objetividade" (2006, p. 320). O método adotado foi o de entrevistas (MINGERS, 2003), com temas esboçados a partir da literatura e objetivos, mas com liberdade para seguir, no seu transcurso, as associações dos entrevistados. Walsham (1995) destaca a importância da entrevista como meio para acessar as interpretações dos participantes com relação a eventos e ações, bem como as suas visões e expectativas.

Uma fase preparatória para a identificação de empresas fornecedoras de TI que poderiam ser consultadas para participar do estudo precedeu o trabalho de campo. Esta fase envolveu a consulta aos profissionais da área e contatos com potenciais participantes. Os critérios para a escolha da fornecedora foram: a) disponibilidade e o compromisso com a participação na pesquisa; b) responsabilidade pela implementação de um ERP em um cliente ainda ativo. A definição da empresa-cliente por sua vez foi feita em conformidade com a fornecedora de TI. Buscava-se um cliente na fase inicial de implementação do ERP, disposto a participar e comprometido com a pesquisa, viabilizando o acesso a dados e a investigação.

A definição da empresa-cliente a ser pesquisada foi bastante difícil, em função da pouca disposição para participar, apresentada por empresas, em função de experiências negativas anteriores com intervenções de psicólogos (uma das pesquisadoras é psicóloga), de demandas de trabalho, de falta de tempo para disponibilizar à pesquisa e da não-percepção de benefícios que pudessem advir da participação no estudo, em combinação com a condição de estar iniciando um projeto. Estas dificuldades derivaram na substituição da proposta original 
Maria Amélia de Mesquita Fetzner \& Henrique Mello Rodrigues de Freitas

de observação, de um processo de implementação em vias de ser iniciado, para um estudo exploratório na pós-implementação de um ERP, como subsídio para estudos posteriores.

A coleta de dados ocorreu no período compreendido entre outubro e novembro de 2008. A indicação de entrevistados foi feita pela responsável pelo sistema na empresa-cliente e teve como critérios a experiência com o sistema e a condição de poder agregar informações úteis para a compreensão da questão em estudo. Não houve disponibilidade dos quadros gerenciais participarem, situação justificada pela prioridade de atenção a assuntos da empresa. Por razões de sigilo, não identificamos a empresa ou os entrevistados. Os participantes foram seis funcionários da empresa, incluindo a responsável pelo sistema. Somente um participante era homem e todos tinham, no mínimo, $2^{\circ}$ grau completo, e duas pessoas tinham nível de pósgraduação. O tempo máximo de empresa era de oito anos Os entrevistados exercem funções nas áreas Financeira, RH, Contábil, Comercial e de Manutenção e fazem uso diário do sistema, como fonte de informação para outros sistemas, para cadastramento e consulta de informações, e para emissão de documentos e relatórios.

A análise dos dados requereu a escuta cuidadosa das entrevistas, com a identificação e organização dos temas, para então elaborarmos um relato sobre o entendimento da experiência dos entrevistados. Onde foi necessário, para clareza do texto, identificamos os entrevistados pela sigla E1, E2 e assim sucessivamente. A teoria foi usada para guiar a construção do roteiro de temas e para trazer insights sobre os dados de campo. Neste estudo, procuramos atentar para critérios de autenticidade, plausibilidade e criticidade (WALSHAM, 2006).

\subsection{O CONTEXTO DE IMPLEMENTAÇÃO}

\subsubsection{A empresa}

A empresa estudada é do ramo de Movimentação de Cargas Vertical e Horizontal. O $E R P$ foi fornecido por uma empresa especializada em soluções de $E R P$, denominada Vensis iii. A empresa-cliente atua há cerca de 30 anos no mercado, atendendo prioritariamente a Região Sul. A empresa fornecedora é uma empresa jovem, cujos sócios demonstram empenho na profissionalização da empresa e preocupação com a qualidade de serviços e com a gestão. Os módulos em uso são: módulo para (controle e o gerenciamento de organizações e de pessoas físicas relacionadas à empresa), o Financeiro, o Contábil, a Ordem de Serviço (integrado à função comercial) e um desenvolvido para o gerenciamento de Equipamentos/Manutenção.

\subsubsection{A empresa para os entrevistados}

Os entrevistados parecem estar de bem com a empresa (grifo nosso), como se observa: 
Repensando questões sobre mudança, afeto e resistência na implementação de SI

Uma empresa bem conceituada no mercado, é uma empresa bem conhecida, porque até conversando com outras pessoas 'onde tu trabalha?', 'ah [slogan da empresa]', já tem aquele registro [...]. É uma empresa boa de se trabalhar, correta, não só com os funcionários dela, mas também em relação meio ambiente, é uma empresa que tá sempre procurando botar equipamentos novos, isto de certa maneira facilita o nosso trabalho... muito diversificada [...].Isto também ajuda no trabalho (E1).

É um desafio eterno e é isto que me motiva aqui. Não é uma empresa que para, justamente por isto, está sempre em mudança, sempre inovando e isto é super bom (E2).

É uma empresa bem conceituada no mercado, está crescendo bastante, desde que entrei aqui até agora teve um crescimento bem considerável, é uma empresa que tem bastante futuro, com bons profissionais Acho que a questão mais é aprimorar, buscar a qualidade, o bom serviço, o atendimento ao cliente, porque esta empresa é uma empresa muito boa (E3).

Eles começaram pequeno e foram crescendo [equipamentos, serviços prestados] [...]. tem tradição no mercado e tem este know how que é excepcional [...]. Poucas têm neste mercado, sabem para onde vai o negócio, têm bem o controle do negócio deles [...]. Uma empresa familiar, isso de buscar a satisfação dos seus funcionários no trabalho, não é só trabalhar, receber seu salário [observa relações duradouras com clientes e preocupação em assistir o funcionário] (E4).

Quanto às pessoas na empresa, as características enfatizadas são a estabilidade ("geralmente quem entra aqui não vai embora"), diversidade (de "perfis", sejam gestores ou funcionários) e flexibilidade da Gestão (nas ações de controle junto aos funcionários e na negociação com clientes). $\mathrm{O}$ ambiente é profissional, convivem formalidade e informalidade. O relacionamento entre colegas é tido como bom, e o controle gerencial, como necessário.

Há referência à integração entre áreas/equipes e a importância de trabalhar em equipe, mas ainda é possível evoluir e "a questão é buscar dentro da empresa esta integração entre as pessoas, comunicação entre os funcionários para melhorar e render mais".

\subsubsection{Início da implementação}

A história do ERP na empresa é similar à de outras empresas, em que a implementação é interrompida ou, como disse uma entrevistada, "a gente teve um contato inicial, depois deu uma esfriada". Com o ingresso da atual responsável pelo sistema iniciou-se uma $2^{\text {a }}$ fase no ano de 2004. Na ocasião, o sistema "estava parado" havia um ano, e não havia ninguém disponível para "tocar isto adiante". Dada a sua vivência prévia em implantação de sistemas, e por ter sentido a necessidade de um sistema para a contabilidade, foi aproveitada na função. 
A decisão pelo $E R P$ veio da necessidade de trocar um sistema com tecnologia antiga, cujo desenvolvedor saíra da empresa. Mesmo sem participação direta no processo de escolha, os funcionários verbalizam a necessidade de um novo sistema, pois o anterior era "bem pequeno", "antigo", "mais complicado" e "já não suportava a necessidade da empresa", que estava crescendo e precisava de mais "recursos”, "rapidez”, "informação”.

Não houve qualquer ação intencional da empresa ou fornecedor sobre a mudança, mas a decisão pela implantação era clara e obrigatória. O sistema foi rodado em paralelo ao antigo durante seis meses, o que dobrava o trabalho e, com isso, relata a responsável, "as pessoas ficavam até mais tarde", mas "foi tranqüilo, a gente decidiu fazer" (...) "claro, isto tem de ter o aval [gerências]". Questionada sobre se houve venda do sistema, pondera "realmente isto foi mal feito, foi assim: vamos, tem que fazer. Teve um erro. Não houve esta venda. Talvez um pouquinho ali, né, vai melhorar, algumas coisas foi conversado, não teve uma reunião".

\subsubsection{Contato inicial dos usuários com o Sistema}

Todos os participantes tinham conhecimento anterior em informática e muitos usam computador, em suas casas. A informática faz parte do dia a dia profissional. Ela é vista como algo "prático", porque "se for depender só do manual tu perde muito tempo" e "fica bem complicado para tu trabalhar". Com a informática se ganha tempo e agilidade no serviço, de modo que "sem computador a gente fica meio perdida", "sem chão".

\subsubsection{Aprendizado}

Houve treinamento e as dúvidas foram sanadas pela responsável ou pelo fornecedor. $\mathrm{O}$ aprendizado teve auxílio ("sempre tem ajuda de alguém, porque não vai abrir um programa e saber fazer as coisas, não sabe de onde vem...") e continua, pois as pessoas 'vão atrás' e fazem descobertas ("muitas coisas das melhorias que a gente fez no sistema era por ficar fuçando, 'vai facilitar se tiver tal coisa', mas usando mesmo é que a gente foi vendo as necessidades do que precisava mudar", por exemplo, reduzir o tempo de operação pela diminuição de janelas). A agilidade depende do uso e deste "pegar afinidade com o sistema".

O período do sistema em paralelo foi usado para "ir treinando, se acostumando". Se por um lado o aprendizado do ERP "foi fácil" e o sistema seja "bem prático" ele é "complexo", pois mesmo conhecendo o que o sistema pode fazer, novas possibilidades surgem e "é um aprendizado constante". Conhecer os processos da empresa antes, para depois "ver como faz dentro do sistema" é importante, porque se não "é muita informação".

\subsubsection{Momento profissional}

Influenciou o contato inicial. Para uma das entrevistadas, era o primeiro emprego, e foi "meio complicado, tu fica meio perdida, até se adaptar às normas, à empresa, mas aos poucos 
Repensando questões sobre mudança, afeto e resistência na implementação de SI

foi tranqüilo". Para outro, o ingresso na empresa requereu o conhecimento da filosofia da empresa e a "adaptação no lado pessoal", mas a experiência anterior auxiliou a "poder pensar com a cabeça do chefe" e como no trabalho [e uso do sistema], "o mais importante é saber o que ele [chefia] quer", "ter esta visão foi ótimo para mim". Para outra, ainda, implicou fazer algo diferente daquilo a que estava acostumada, e representou "arriscar para o nosso trabalho, porque quando [o ERP] chegou, era bem cru e realmente dava mais trabalho de fazer".

\subsubsection{Avaliação da implementação}

Os entrevistados de modo geral não avaliaram a implementação como difícil. A exceção é feita pela responsável, para quem "toda implantação de sistema é muito difícil, porque todas as pessoas têm uma restrição imensa à mudança, isto é muito claro”. A razão é que as pessoas enxergam o trabalho no momento e "é muito difícil quando tu não estás enxergando a melhoria agora", quando "não conseguem ver o retorno que terão mais adiante".

\subsubsection{Mudanças no Sistema ao longo do tempo}

A implementação não está concluída. O sistema está "em constante desenvolvimento" $\mathrm{O}$ desenvolvimento permitiu que a empresa triplicasse de tamanho nos últimos anos e a quantidade de funcionários da área administrativa permanecesse praticamente a mesma.

Há uma grande diferença e evolução no sistema em relação ao início do seu uso. Ele foi "bem aprimorado", houve bastante "mudanças para melhor", "está bem mais fácil" e "facilita o serviço". Melhorias são constantes e derivam da percepção de dificuldades e sugestões, como se observa no depoimento a seguir:

Todo nosso processo já estava dentro do sistema, só que nos tínhamos algumas dificuldades, coisas que poderiam nos ajudar e aí sentei com a [responsável], quem sabe a gente ajeita, vamos ver como fica melhor, dá para fazer, não dá para fazer, tudo envolve custo também, então, não depende só da gente querer que seja daquela maneira, depende da Direção (E1).

Surgem novas necessidades com o ERP: “ele é ótimo, mas tu começas a ver, é como se o ERP estivesse pedindo, eu preciso de outras coisas". Para as melhorias, contam a relação com a fornecedora de TI, e a confiança dos entrevistados no entendimento e resposta às suas necessidades. Geralmente “o retorno é bom”, embora "de vez em quando, mas isto é normal, eles [fornecedor] dizem que não dá, acham que não vai dar para fazer, isto não pode...”.

\subsection{AS PESSOAS NA IMPLEMENTAÇÃO DO ERP}

\subsubsection{Receptividade e resistências}

Nem os todos entrevistados acompanharam a implementação desde o início, mas os relatos feitos permitem ter uma noção sobre a receptividade inicial: 
$\mathrm{Tu}$ passa o tempo inteiro escutando que o outro sistema era melhor, mais fácil. Diziam: no outro tu fazia assim [...] tem esta resistência (E2).

Tudo que é novo gera burburinho, mas foi avisado para todo mundo, 'a partir de hoje vai ficar paralelo'. Ficou paralelo até o pessoal se adaptar às novidades [...]. O sistema mesmo se adaptar à empresa, já era um sistema pronto [...]. A gente teve de se adaptar, tem este tipo de dificuldade [...]. Não teve assim problema [...]. O pessoal aceitou bem, acho que todo mundo ficou feliz. Eu gosto de coisa nova. Gosto de cultura nova. Eu fiquei contente (E5).

Tudo que é diferente tem uma resistência [...]. Como a gente passou de um sistema, como vou dizer, muito simples, precário na parte de informação assim, é... tudo que é novo é complicado. Então fica difícil a aceitação, não pelo sistema, em si, mas por ter de mudar completamente a sistemática de trabalho, mas hoje o pessoal já tá bem adaptado, inclusive melhorou bastante o sistema, tem facilitado bastante a nossa vida [...] O pessoal tem gostado bastante, elogiam o sistema. Num primeiro momento sempre choca um pouco assim né, mas quando começa a trabalhar e vê que facilita... [...] Tudo que é novo preocupa, será que vai dar certo...será que não vai dar, mas no fim acaba dando certo (E1).

É complicado (riso). Bastante. Até dominar... todo mundo não gosta (E3).

A expectativa inicial frente ao sistema, na opinião da responsável, era de que "não vai funcionar", porque "mudança, ninguém gosta de mudar, para que mudar se esta funcionando assim?". Para a resistência conta a diferença em relação ao sistema anterior, que "não era um sistema que desse segurança, podia ser burlado com facilidade, tu criava o que tu querias". Para a responsável, a resistência foi superada "com o tempo", mas "teve gente que não se adaptou e teve de sair". Houve também um processo intencional de influência entre colegas:

A gente então foi atrás para mostrar, para convencer que realmente o sistema facilitava a nossa vida [...] Eu brincava muito no sistema, eu mexia e abria janela, nem entendia nada, eu abria, olhava, fui descobrindo coisas assim e fui colocando no nosso dia a dia. Se alguém perguntava, 'mas tal coisa?'. 'Sabia que o sistema faz isto?' Mas como? Aí eu ia lá, ensinava, mostrava. Via as idéias deles, mas se fosse assim era melhor, vou falar com a [responsável]. Daí tá todo mundo falando, chegava com a gurizada ali, via o que todo mundo achava e passava para a [responsável]. Foi assim que a gente foi fazendo nossas melhorias, baseado nas idéias de todo mundo (E1).

Há a percepção de diferentes reações das pessoas diante de um novo sistema, e há as que "têm mais dificuldade, não por causa do sistema, mas com o computador, de uma maneira em geral”, e "daí é uma questão delas, não do sistema”. As diferenças podem envolver, por exemplo, facilidade para aprender e capacidade de concentração. 
Repensando questões sobre mudança, afeto e resistência na implementação de SI

\subsubsection{Afetividade ${ }^{\text {iv }}$ : emoções, sentimentos, estados de espírito}

O sistema provoca reações de agrado ou desagrado, as quais podem mudar com a experiência com o sistema. Emoções negativas surgem frente à frustração, quando "às vezes a pessoa está braba porque não consegue fazer uma coisa dentro do sistema" e "a gente ouve 'ah, porque o sistema é uma porcaria, porque não presta'”. Muitas vezes, com auxílio, a pessoa fica sabendo que é possível realizar a operação pretendida no sistema e em outras, as falhas atribuídas ao sistema ocorrem porque "o sistema não funciona sozinho, tem que alimentar ele com informações,... ele não é mágico, não imagina que alguém saiu e vai lá e registra". Mas às vezes, realmente não é possível realizar a operação no sistema e a reação é "que droga, tem tudo aqui e não consigo". Mas, neste caso, "o bom é que gera melhoramentos".

As emoções positivas, por outro lado, são associadas às facilidades e ao sentido encontrado no trabalho com o sistema, como expresso nos comentários a seguir:

Achei, acho e continuo achando que melhora a nossa vida, entendeu? É muito mais fácil para nós usar o sistema do que ficar dependendo de um papelzinho, uma planilha, sabe [...] eu tive uma oportunidade com o sistema até porque era a que mais usava e porque eu gosto, tem gente que não gosta desta parte mais burocrática, eu gosto, não tive maiores problemas. Muito pelo contrário... aumentou o trabalho, né, porque as perguntas vêm para mim, mas é uma coisa que eu gosto, gosto de estar em função do sistema. Gosto quando está funcionando (E1).

É uma vitória... eu amo isto, adoro isto, este trabalho de desenvolvimento (E2).

As emoções positivas são associadas também às melhorias feitas no sistema ao longo do tempo. O sistema é permanentemente "customizado", e a emoção é a de "mais isto aí, tu consegue depois de um tempo ver que passou... ah, agora tem, tu fica satisfeito porque sabe que tu mesmo fez, fez parte daquele processo"'[...].Aquilo que a gente pediu foi implementado". Tanto que:

Com as últimas melhorias que a gente fez eles têm elogiado bastante, de uma maneira geral as pessoas tem gostado, não chegam a dizer que é maravilhoso, né? (riso), mas a gente tem uma aceitação boa digamos assim, no geral, eles vêem também o meu esforço, o esforço da [responsável] em tentar melhorar (E1).

A idéia de que há uma boa aceitação geral do sistema é compartilhada e refletida no sentimento de que "o pessoal está bem satisfeito, não vou dizer super satisfeito, é claro que para chegar num grau ótimo ainda precisa mais alguma coisa”. Além disso, a satisfação com o 
sistema varia de pessoa para pessoa, pois "é claro sempre tem um grau de dificuldade de cada pessoa, dependendo de ela saber utilizar ou não, se aprendeu a utilizar ou não".

A ansiedade pelas perdas aparece na reação à troca de um quadro de agendamentos manual no setor comercial, afixado na parede, para o sistema informatizado. Embora o agendamento, via sistema, tivesse sido elogiado enquanto foi mantido em paralelo, no momento em que o quadro foi retirado, houve aquele "ai meu Deus, cadê o quadro, cadê o sistema?". Isto faz com que no momento ainda sejam mantidos alguns papéis, "justamente por ser um apego de ter uma coisa palpável, sabe, eu diria esta dificuldade de ter só no sistema". A troca deste quadro também exemplifica o modo pelo qual o uso do sistema foi influenciado por colegas, visto na explicação de que foi colocado num lugar "meio ruim", "para incentivar o pessoal a usar o sistema”. É percebida a diferença entre as pessoas que acompanharam todo o processo de ajustes no sistema e "passaram por certo estresse" e as que ingressaram posteriormente na empresa. Também é percebida uma maior ansiedade na responsável.

O processo de desenvolvimento em aberto gera sentimentos e emoções contraditórios, pois se por um lado faz aumentar a satisfação, e "diminuiu o stress de se preocupar tanto, porque o sistema tá fazendo por ti", por outro "aumenta a ansiedade", "de ver funcionar, como vamos implantar isto aqui?". Neste sentido, as necessidades de melhorias apontadas dizem respeito a aspectos humanos, tal como o da conscientização de que é preciso "colocar informações no sistema para ele rodar direitinho" ou de "ampliar a comunicação pelo sistema e não precisar ficar confirmando informações com outras pessoas".

\subsubsection{Significado do Sistema}

Os entrevistados usam com freqüência o sistema, embora alguns façam uso mais limitado de suas funções e utilizem mais outros sistemas. Atualmente, é muito importante e, sem o sistema, o trabalho ficaria dificultado, com aumento de carga de serviço, maior dispêndio de tempo e atraso na realização de tarefas e conseqüências negativas para o serviço, que poderia ficar "incompleto", "sem informação", até o ponto de não poder ser realizado ou de prejudicar o negócio. Alguns poderiam realizar parte do serviço sem o ERP, porque mantêm documentos em papel (por exemplo, uma planilha que "não é para usar, mas ainda não é o momento de se desfazer dela...”) ou poderiam fazer algo manualmente. De qualquer forma, iria "atrapalhar bastante" e o sistema é visto até mesmo como tão importante que "não dá para viver sem ele".

A par de significados no contexto de trabalho dos entrevistados, também há menção ao que o sistema representa profissionalmente. Assim, para a responsável pelo sistema, ele é uma "vitória", para outra entrevistada trabalhar com o sistema foi uma "oportunidade" e esta não 
Repensando questões sobre mudança, afeto e resistência na implementação de SI

vê como uma responsabilidade o fato de os colegas geralmente se dirigirem a ela quando têm uma dúvida sobre o sistema. Seu posicionamento pode ser visto na afirmação a seguir:

Adotei ou vamos fazer este negócio funcionar ou então vamos largar ele de vez. Porque não tinha assim interesse, sabe, não havia um interesse e a coisa estava engatinhando e não saía do lugar. Não, vamos assumir este negócio porque precisava alguém [na área], não tô dizendo que tinha que ser eu, podia ter sido qualquer pessoa (E1).

O sistema tem significado central para a empresa, permitindo crescimento, controle, a própria essência da gestão atual. Alguns comentários traduzem sua importância:

O resultado é isso, tu ter esta quantidade de informações integradas, sem ter de ir aos setores (E4).

Na verdade hoje é o que comanda toda a operação. É importante, é tudo. Teve uma facilidade [...]. Muita coisa que fazia manualzinho, com um controlezinho hoje tu consegue ter com um suporte maior. $\mathrm{O}$ resultado é aí (E5).

Toda gestão da empresa tecnicamente. Dá custos, preço de venda, margem gerencial, tudo. Os funcionários hoje têm bem claro que a mudança foi muito importante para o crescimento da empresa, acompanhamento. Hoje, jamais conseguiríamos ficar com as informações que tínhamos no nosso sistema antigo e gerenciar. Hoje, com certeza, estaríamos perdidos (E2).

\subsubsection{Mudanças}

Questionados quanto a se e em quê o ERP mudou o seu trabalho, os entrevistados em sua maioria dizem que não houve muitas mudanças na "essência da função". Mas citam alterações em relação ao sistema anterior e ao próprio ERP ao longo do tempo, entre as quais: diferenças visuais [apresentação], possibilidade de inserir um maior número de informações, redução de cálculos manuais, maior facilidade para consulta e recuperação de informações, acesso a informações por todos (números de telefone, por exemplo), maiores recursos e opções, melhorias e redução de trabalho na emissão de notas fiscais e relatórios, redução de uso de papel e de retrabalho (digitação). A alteração em rotinas na realização de tarefas (por exemplo, no agendamento de serviços e na emissão de notas fiscais) e no contato com outros profissionais/supervisão pelo uso do sistema não foram percebidas como significativas. Assim, a percepção dos entrevistados sobre mudanças parece guiada, num primeiro momento, pela avaliação de mudanças ou não na razão de ser do trabalho.

Mas, se a razão de ser do trabalho permaneceu a mesma, outros aspectos não. $\mathrm{O}$ sistema representou, por exemplo, uma nova experiência e uma grande diferença para um dos entrevistados, que nunca havia trabalhado com um sistema de gestão e percebeu ter demorado mais do que o habitual no aprendizado em função da complexidade do sistema e das muitas 
informações de que dispõe. Descobertas, como "ah, a gente pode usar isto para tal coisa e a gente não tá usando" acontecem, de tal modo que a percepção é de que "dentro do Vensis tu tá criando" e que os novos desenvolvimentos podem levar, aí sim, a alterações na natureza do trabalho. O comentário a seguir ilustra essa possibilidade:

Não estou querendo que o sistema faça o meu trabalho, mas na verdade o teu trabalho vai ser verificar se as informações estão corretas. Vai simplificar, tu não vai trabalhar tanto como analista e mais como auditor (E4).

Houve uma mudança para todos em termos da responsabilidade de alimentar o sistema com os dados necessários para a execução do trabalho e as mudanças relacionadas ao sistema envolveram a adaptação tanto das pessoas como do sistema, como já mencionado na seção sobre receptividade, situação esta que também é ilustrada na fala a seguir:

Ele se encaixou bem no nosso sistema de trabalho, nós que adaptamos ele no nosso sistema de trabalho. No começo nós nos adaptamos um pouco a ele, porque como eu te falei ele era bruto. Só usando para saber o que era o que precisava mudar para melhorar o nosso trabalho ou não. Ele acabou ficando de um jeito que assim cada vez mais ele ia nos facilitando (E1).

O sistema aparece como associado à mudança na empresa e como elemento de sustentação essencial no seu crescimento. Ele "mudou bastante todo o processo da empresa" e o seu sistema de trabalho. Hoje, todos fazem uso do sistema diariamente. Por sua vez as mudanças baseiam-se em melhorias que o sistema poderá trazer: "depois do ERP tu visualiza um mundo de possibilidades que não tinha antes" [...] "poderia ter isto, melhorar, não que esteja ruim". A responsável lembra de que não havia muitas mudanças na empresa, "até que se começou a se mudar". Hoje as mudanças são muitas e rápidas, abarcando ao longo dos últimos quatro anos diversos investimentos, em sistema, equipamentos, ambiente físico. "Talvez, um perfil da nossa empresa seja isto... estamos eternamente em implantação, eterna mudança”, o que se tornou mais fácil, porque as pessoas se acostumaram com a mudança.

\subsubsection{Uso geral do sistema}

Os entrevistados mencionam pessoas que não fazem uso de todas as possibilidades do $E R P$. Esses colegas não foram ouvidos para que pudessem explicar o que acontece, já que “eles sabem fazer, só que não fazem...”, mas os comentários dos entrevistados indicam que os motivos não decorrem de falta de conhecimento ou de dificuldades de operação, como podemos observar:

Eu acredito que seja por preguiça, porque não tem outra lógica. Não vai me dizer que não sabe como funciona, gente que trabalha aqui há 
Repensando questões sobre mudança, afeto e resistência na implementação de SI

muito mais tempo do que eu...não acredito que não saiba como o sistema funciona (E3).

Sinceramente, não sei (riso), não é por falta de conhecimento, expliquei um por um, expliquei o processo todo certinho e então se alguém tem alguma dificuldade eu tô sempre ali, é só perguntar. Não sei que tipo de resistência tem... não sei explicar (E1).

Como consequiência, é preciso sair em busca ou lançar informação e, eventualmente, podem ocorrer perdas no serviço. De todo modo, informar e manter o sistema atualizado, seria "o certo" e "funcionaria bem melhor".

\section{DISCUSSAO}

A análise do caso remete, em vários aspectos, às abordagens teóricas, tais como o da natureza ambígua da situação de mudança associada com TI/SI, e de suas diferentes interpretações; as variáveis individuais e situacionais influindo no curso do processo; as resistências como algo a ser compreendido, ao invés de inapropriado por si; reações não homogêneas das pessoas e relacionadas a respostas a outras facetas de uma organização.

O desenvolvimento e a implementação do sistema foram e continuam a ser feitos, sem conformidade estrita com um plano prévio, como enfatiza a Metáfora da Hospitalidade (CIBORRA, 2002). A despeito de o ERP ser uma tecnologia mais estruturada, o fornecedor de TI conduziu a implementação dando suporte e respeitando as necessidades e o processo de crescimento vivido pela organização, de tal modo que houve uma adaptação mútua entre o sistema e a organização e seus processos de trabalho. Pode-se observar a característica de cultivo implicada na adoção do ERP, e de como uma tecnologia é modelada pela cultura do contexto onde é desenvolvida (SACCOL; REINHARD, 2006).

$\mathrm{Na}$ interação com a organização, o sistema foi facilitando os processos e a tecnologia assumiu predominantemente o caráter de "amiga" (CIBORRA, 2002). O modo bem sucedido como foi hospedada decorreu de vários fatores, como o de ter sido desenvolvida e adaptada às necessidades da organização, da relação positiva dos usuários com a empresa, da condição de participação no processo, da concordância com a necessidade de mudança e do aprendizado realizado. A aprendizagem envolveu o "aprender fazendo" e o ganho de afinidade com o sistema, que reforça o seu uso mais habilidoso. Foram relatadas as descobertas pelo uso, o compartilhamento de experiências e conhecimento sobre potencialidades da tecnologia e a troca de idéias sobre necessidades e melhorias, na interação com colegas. A diversidade de reações perante uma nova TI aparece nos diferentes níveis de aceitação e uso do ERP. 
O sistema está incorporado no dia a dia dos entrevistados, revelando um elevado grau de apropriação da tecnologia. Não recolhemos evidências suficientes para indicar como a improvisação se deu, neste caso, e também não acompanhamos o desenrolar do processo de mudança individual, mas os relatos dos entrevistados indicam tipos de mudanças pessoais na experiência com o $E R P$, em aspectos como: a) práticas de trabalho (maior facilidade e rapidez na execução de tarefas e redução de retrabalho); b) adaptação e descobertas pessoais (aprendizado, nova sistemática de realização do trabalho e novas responsabilidades); c) relacionamento com a informação (facilidade para trabalhar com maior quantidade de informação, ampliação da oferta de informação para todos); d) postura frente à mudança (maior abertura das pessoas à mudança).

Ciborra (apud SACCOL; REINHARD, 2006), diz que, de certa forma, redefinimos nossas identidades no relacionamento com uma nova tecnologia, alterando tarefas, expectativas, compromissos, em um processo que não é unidirecional, pois a tecnologia também pode ser alterada. Esta possibilidade ficou evidenciada nas alterações de interface e nas novas funcionalidades e desenvolvimentos. Em relação às pessoas, chamam atenção as afirmativas de que não houve basicamente mudança no escopo do trabalho individual, na "essência da função", embora os entrevistados tenham mencionado alterações em rotinas, responsabilidades, novas atribuições e processo pessoal de aprendizado. Quanto à organização como um todo, foi citada uma mudança expressiva no processo de trabalho e no perfil, de "uma empresa que não mudava" para uma em "eterna mudança". Temos aqui duas reflexões. Uma é a de que, dependendo do conceito usado, teremos entendimentos diversos sobre se há ou não redefinição de identidade no relacionamento com novas tecnologias. Outra é a de que a diferença nas percepções pode estar ligada ao maior ou menor distanciamento com que se observam as mudanças (WEICK; QUINN, 1999).

A afetividade na interação com a tecnologia é expressa por afetos de matiz positivo e negativo (CENFETELLI, 2004). Positivo, em afirmativas do tipo "amo isto", "gosto quando tá funcionando", alusão às facilidades ("melhora a nossa vida"), à satisfação por ter feito parte do processo de melhoria; e negativo, frente à frustração, quando as pessoas ficam "brabas" ou aumenta a sua "ansiedade". Emoções negativas podem ser revistas, mediante o auxílio em dificuldades, pelo conhecimento de funcionalidades não percebidas em um primeiro momento e pela percepção de contribuir para a solução de problemas e necessidades. É interessante notar as facetas contraditórias do sistema, pois ao mesmo tempo em que gera satisfação pelo que faz, também gera ansiedade pelo que pode vir a ser feito. Isso nos remete especialmente à ambigüidade de emoção diante de novas TICs (ZORN, 2002; CIBORRA, 2002) e à 
Repensando questões sobre mudança, afeto e resistência na implementação de SI

racionalidade reflexiva na prática de SI (McGRATH, 2006). Observamos a tentativa de influenciar interpretações e experiências e o uso da expressão emocional de modo instrumental, enquanto não constatamos o trabalho emocional de agentes de mudança e de regras para exposição emocional (ZORN, 2002).

Outro aspecto a ressaltar é a ênfase sobre diferenças que existem nas reações das pessoas, fundadas sobre suas experiências anteriores e suas características individuais, reforçando a idéia da diversidade de interpretações que se fazem sobre uma dada tecnologia e até mesmo nuances interpretativas, como a do usuário, para o qual o ERP não é difícil, mas é complexo.

Com relação à interpretação e significados conferidos ao sistema, vemos que há percepções coincidentes, o que não significa afirmar um significado comum para o fenômeno (SILVA; VERGARA, 2003). O sistema aparece como muito importante para a realização do trabalho, central na gestão da empresa e oferecendo suporte ao seu crescimento, com significados particulares ilustrados nos comentários sobre ser uma "vitória" ou "oportunidade", e no uso, por alguns, de termos que personalizam o sistema ("pegar afinidade com o sistema", "como se o ERP estivesse pedindo").

Ciborra (2002) destaca a importância do projeto profissional dos participantes e de seus estados de espírito no sucesso de uma implementação. No caso, nos parece ser de especial relevância a experiência anterior e o projeto profissional da responsável pelo sistema, no momento do ingresso na empresa, que aliados à autoridade nela investida pela Gestão, influenciaram decisivamente o processo. $\mathrm{O}$ momento profissional de entrevistados no contato inicial com o sistema (primeiro emprego, ingresso na empresa, algo que envolveu arriscar), também influiu sobre a relação estabelecida com o ERP.

Os entrevistados (GEORGE; JONES, 2002; CIBORRA, 2002) transmitem um sentimento global positivo em relação à organização. Para tal, contribuem a idéia de que é uma boa empresa, de que trata bem seus funcionários e o tipo de condução da implementação. Esta, mesmo sem um "discurso" participativo, e não intencionalmente, oportunizou às pessoas terem clareza sobre a necessidade da mudança, serem ouvidas em sugestões e necessidades e se perceberem como sujeitos na situação (SILVA; VERGARA, 2003; MCGRATH, 2006).

Nas verbalizações dos entrevistados as resistências são referidas a outras pessoas, e de acordo com o pressuposto de ser um "fato da vida", a ser esperado, já que os seres humanos são naturalmente resistentes à mudança (HERNANDEZ; CALDAS, 2001). Elas foram sendo tratadas, por exemplo, via influência sobre colegas. Isto é ilustrado pelo comentário de um usuário, dizendo que problemas causam ansiedade, mas são também uma oportunidade. 
Ter presente a mudança individual, como um processo em que elementos cognitivos e afetivos estão em interação (GEORGE; JONES, 2001), dá unidade à análise deste caso.

\section{CONSIDERAÇÕES FINAIS}

Dentre as principais limitações deste estudo estão: 1) o enfoque no âmbito individual, sem um exame mais aprofundado do contexto organizacional e institucional e sem o entendimento de relações entre esses âmbitos; 2) o recorte no tempo e o caráter retrospectivo, sem o exame do desenrolar do processo e sujeito à recordação dos entrevistados; 3) o grupo de entrevistados não ter sido mais amplo, para abarcar outras experiências e visões. Sugerimos como desenvolvimento deste estudo, investigações longitudinais e realizadas na ótica de processo e aplicadas a outras situações, contextos e tecnologias.

$\mathrm{O}$ artigo responde à sugestão de estudos examinando a afetividade na experiência com SI. Os resultados, como contribuições teóricas para a área, reforçam a presença da afetividade ao longo do processo e mostram a interação entre elementos cognitivos e afetivos e as suas várias expressões - emoções, estados de espírito, sentimentos e atitudes, trabalho emocional. Uma segunda contribuição é ampliar a visão sobre como as pessoas constroem a vivência da mudança associada com TI/SI (inclusive quanto à resistência) a partir de suas circunstâncias (momento e projeto profissional, características pessoais, experiências anteriores), da sua relação com a empresa e da forma como esta conduz o processo. Uma terceira é destacar um ponto que tem consequiências muito diretas na prática de profissionais da área, e que se refere ao paradoxo que se cria quando a satisfação com a informática gera necessidades crescentes.

Propusemos elementos para reflexão sobre processos de implementação de TI/SI, entendendo que a natureza e o escopo da mudança exigem abordagens amplas da inovação em SI, implicando novos conhecimentos e competências, e também o desafio de transpor conhecimentos gerados no ambiente acadêmico para a realidade dos profissionais.

\section{REFERÊNCIAS}

BARRET, M.; GRANT, D.; WAILES, N. ICT and organizational change: Introduction to the special issue. Journal of Applied Behavioral Science, Arlington,v. 42, n. 1, p. 6-22, Mar. 2006.

BARSADE, S.; GIBSON, D. Why does affect matter in organizations? The Academy of Management Perspectives, Birmingham, v. 21, n. 1, p. 36-59, Feb. 2007. 
Repensando questões sobre mudança, afeto e resistência na implementação de SI

CENFETELLI, R. T. Getting in touch with our feelings towards technology. In: ACADEMY OF MANAGEMENT ANNUAL CONFERENCE, 2004, New Orleans. Best Paper Proceedings ... New Orleans, 2004.

CIBORRA, C. Hospitality and IT. Amsterdam: University of Amsterdam, 1999. Working Paper 99-02.

CIBORRA, C. In the mood for knowledge: a new study of improvisation. London: London School of Economics and Political Science, 2001. [Working paper]

CIBORRA, C. The Labyrinths of Information: Challenging the wisdom of systems. New York: Oxford Press, 2002.

CIBORRA, C.; WILLCOCKS, L. The mind or the heart? It depends on the (definition of) situation. Journal of Information Technology, Oxford, v. 21, p. 129-139, 2006.

GEORGE, J.; JONES, G. Towards a process of model of individual change in organizations. Human Relations, London, v. 54, n. 4, p. 419- 440, Apr. 2001.

HARLEY, B. et al. Management reactions to technological change: The example of enterprise resource planning. Journal of Applied Behavioral Science, Arlington, v. 42, n. 1, p. 58-75, 2006.

HERNANDEZ, J. M. C.; CALDAS, M. P. Resistência à mudança: Uma revisão crítica. Revista de Administração de Empresas, São Paulo, v. 41, n. 2, p. 31-45, abr./jun. 2001.

MCGRATH, K. Affection not affliction: The role of emotions in information systems and organizational change. Information and Organization, Shannon v.16, n. 4, p. 277-303, 2006.

MINGERS, J. The paucity of multimethod research: A review of the information systems literature. Information Systems Journal, Parkview Square v.13, n. 3, p. 233-249, June 2003.

ORLIKOWSKI, W.; GASH, D.C. Technological frames: Making sense of information technology in organizations. ACM Transactions on Information Systems, Pittsburgh, v. 12, n. 2, p. 174-207, Apr. 1994. 
ORLIKOWSKI, W. Using technology and constituting structures: A practice lens for studying technology in organizations. Organization Science, Pittsburgh, v. 11, n. 4, p. 404428, Jul. /Aug. 2000.

RODRIGUES FILHO, J. , LUDMER, G. Sistemas de Informação: Que Ciência é Essa? Revista de Gestão da Tecnologia e Sistemas de Informação, São Paulo, v. 2, n. 2, p. 151$166,2005$.

SACCOL, A. Z.; REINHARD, N. The hospitality metaphor as a theoretical lens for understanding the ICT adoption process. Journal of Information Technology, Oxford Inglaterra, v. 21, n. 3, p. 154-164, 2006.

SILVA, J. R.; VERGARA, S. Sentimentos, subjetividade e supostas resistências à mudança organizacional. Revista de Administração de Empresas Eletrônica, São Paulo, v. 43, n. 3, p. 10-21, jul./set. 2003.

WALSHAM, G. Intepretive case studies in IS research: nature and method. European Journal of Information Systems, Hampshirev. 4, p. 74-81, 1995.

WALSHAM, G.. Doing interpretive research. European Journal of Information Systems, Hampshire, v. 15, n. 3, p. 320-330, 2006.

WEICK, K.; QUINN, R. Organizational change and development. Annu. Rev. Psychol, Palo Alto, v. 50, p. 361-86, Feb. 1999.

WEICK, K; SUTCLIFFE, K.; OBSTFELD, D. Organizing and the process of sensemaking. Organization Science, Pittsburgh, v. 16, n. 4, p. 409-421, July /Aug. 2005.

VAAST, E.; WALSHAM, G. Representations and actions: The transformation of work practices with IT use. Information and Organization, Shannon v. 15, n. 1, p. 65-89, 2005.

ZORN T. E. The emotionality of information and communication technology implementation. Journal of Communication Management, London, v. 7, n. 2, p. 160-171, 2002.

\footnotetext{
${ }^{i}$ Apresentação realizada no $4^{\circ}$ CONTECSI - Congresso Internacional de Gestão de Tecnologia e Sistemas de Informação. 31 de Maio de 2007, USP/São Paulo/SP.

ii No artigo, os termos TI e TIC foram usados como equivalentes.
} 
Repensando questões sobre mudança, afeto e resistência na implementação de SI

\footnotetext{
iii Para conhecer a empresa, pode ser acessada a sua homepage no endereço: http://www.vensis.com.br/

${ }^{\text {iv }}$ A afetividade inclui emoções (ligadas a causas específicas, geralmente intensas e de curta duração); estados de espírito (na forma de um sentimento global positivo ou negativo, em geral difuso); sentimentos (refletem uma avaliação de um objeto em particular); trabalho emocional (indução ou supressão de sentimentos, buscando uma expressão externa que produza um estado mental apropriado em outras pessoas) (BARSADE; GIBSON, 2007).
} 